\title{
Screening for Intrauterine Growth Restriction in Uncomplicated Pregnancies: Time for Action
}

\author{
Suneet P. Chauhan, MD ${ }^{1}$ Dwight J. Rouse, $\mathrm{MD}^{2}$ Cande V. Ananth, PhD, MPH ${ }^{3}$ \\ Everett F. Magann, MD ${ }^{4}$ Eugene Chang, MD ${ }^{5}$ Joshua D. Dahlke, MD ${ }^{2}$ Alfred Z. Abuhamad, MD ${ }^{1}$
}

${ }^{1}$ Department of Obstetrics and Gynecology, Eastern Virginia Medical University, Norfolk, Virginia

2 Brown University, Warren Alpert Medical School, Providence, Rhode Island

${ }^{3}$ Department of Obstetrics and Gynecology, College of Physicians and Surgeons, Columbia University, New York, New York

4 University of Arkansas, Little Rock, Arkansas

${ }^{5}$ Medical University of South Carolina, Charleston, South Carolina
Address for correspondence and reprint requests Suneet $\mathrm{P}$. Chauhan, MD, 845 Fairfax Avenue, Suite 544, Norfolk, VA 23507 (e-mail: chauhasp@evms.edu); reprints are not available from the corresponding author.

Am J Perinatol 2013;30:33-40.

\begin{abstract}
Keywords

- IUGR

- perinatal outcomes

- third-trimester sonography

- SGA

A randomized clinical trial (RCT) noted that sonographic examination in the third trimester, in conjunction with delivery at term for abnormalities of fetal growth, significantly decreased the likelihood of small-for-gestational-age (SGA) neonates in uncomplicated pregnancies. We identified 15 characteristics of screening tests and attempted to determine if there is evidence to routinely obtain sonographic estimates of fetal weight in the third trimester and decrease rates of SGA. Of the 15 suggested characteristics, currently 10 (67\%) are fulfilled, two are uncertain (sonographic examination is cost-effective or reliable), and one (the test must do its job) is possibly valid. Due to the lack of RCTs demonstrating reduction in morbidity, there is potential for leadtime and length bias. To observe a $36 \%$ decrease (from 4.1 to $2.6 \%$ ) decrease in composite perinatal morbidity, 6000 women need to be randomized to at least two sonographic examinations in the third trimester versus routine prenatal care. Such an RCT is warranted and justified.
\end{abstract}

According to the American Congress of Obstetricians and Gynecologists (ACOG) practice bulletin, ${ }^{1}$ estimated fetal growth below the 10th percentile for gestational age (GA) is intrauterine growth restriction (IUGR), and standards based on birth weight refer to small for gestational age (SGA). IUGR is "one of the most common and complex problems in modern obstetrics." It is linked with low Apgar scores and umbilical arterial $\mathrm{pH}<7.00$; admission to a neonatal intensive care unit and sepsis; increased stillbirth and neonatal mortality risks; learning difficulties and adultonset cardiovascular disease. ${ }^{1}$ There is an imperative to prenatally identify growth restricted fetuses because, according to the practice bulletin, the neonatal mortality among detected newborns with birth weight $<10$ th percentile for GA

received

November 23, 2011

accepted after revision

March 31, 2012

published online

July 6, 2012 is $8 / 1000$ births compared with $21 / 1000$ births for undetected newborns. The current recommendations for identification of growth-restricted fetuses are to obtain third-trimester sonographic estimates of fetal weight (SEFWs) in high-risk pregnancies and to perform serial fundal height measurement in low-risk pregnancies at each clinic visit. Among lowrisk pregnancies, SEFWs should be reserved if there is lagging fundal height or no change in fundal height between examinations. ${ }^{1}$

In 2003, McKenna et $\mathrm{al}^{2}$ published a randomized clinical trial (RCT) that assessed the utility of two sonographic examinations in low-risk women. They reported that women who had an SEFW at 30 to 32 weeks and at 36 to 37 weeks were significantly less likely to have SGA newborns (10.4\%
Copyright (c) 2013 by Thieme Medical Publishers, Inc., 333 Seventh Avenue, New York, NY 10001, USA. Tel: +1(212) 584-4662.
DOI http://dx.doi.org/ 10.1055/s-0032-1321497. ISSN $0735-1631$. 
versus $6.9 \%$, respectively; relative risk 0.67 ; $95 \%$ confidence intervals $0.50,0.89$ ) compared with those followed with fundal height measurements alone. The investigators concluded that although the two sonographic examinations and inductions for abnormalities noted with them increased interventions, they significantly reduced the risk of suboptimal growth. Currently the ACOG practice bulletins on IUGR ${ }^{1}$ and on ultrasonography in pregnancy ${ }^{3}$ do not recommend screening uncomplicated women with additional sonograms to assess fetal growth after 30 weeks.

One explanation for the lack of a recommendation in the bulletins for SEFW in low-risk women is that it does not meet the criteria for screening. As noted by Rouse et al, ${ }^{4}$ as well as Grimes and Schulz, ${ }^{5}$ inappropriate screening can lead to unnecessary obstetric intervention and harm. The purpose of this commentary is to determine whether sonographic examinations in the third trimester meet the criteria for screening tests.

\section{Criteria for Screening Tests}

We identified 15 characteristics for a useful screening test (-Table 1). ${ }^{4,5}$ First, the disease should be medically important. Undeniably IUGR is important because it is associated with obstetric (stillbirth, oligohydramnios, cesarean delivery for nonreassuring fetal heart) and neonatal (hypothermia, sepsis, seizure) complications, as well as an increased risk of neonatal and infant mortality. ${ }^{6}$ Second, the disease should be clearly defined. Though there are several definitions of IUGR (birth weight below $3 \%, 5 \%, 10 \%$, or $15 \%$ for GA) both ACOG and Royal College of Obstetricians and Gynaecologists (RCOG) acknowledge that birth weight $<10$ th percentile is growth restriction. ${ }^{1,7,8}$ IUGR is diagnosed when, during sonographic examination, abdominal circumference $(A C)$ or estimated fetal weight is $<10 \%$ for GA. ${ }^{1}$ Third, the prevalence should be known. ${ }^{1}$ By strict definition, the prevalence of suboptimal growth is $10 \%$.

Fourth, the natural history should be known. ACOG has identified 33 risk factors, which are categorized as 24 arising from maternal causes, six placental and three with fetal origins. ${ }^{1}$ The understanding of IUGR due to uteroplacental insufficiency is that cytotrophoblast invasion is shallow and endovascular invasion is rudimentary in placental development leading to poor perfusion. Morphologic placental studies have noted that the mean surface area as well as the capillary surface area is reduced. Results of cordocentesis reveal that pregnancies complicated by IUGR have fetal hypoxemia, acidosis, hypoglycemia, $\alpha$-amino nitrogen, and especially branched chain amino acids. ${ }^{9}$ Reduced urinary output is associated with oligohydramnios, which in turn is linked with cord compressions and stillbirth. ${ }^{1}$ Long-term adverse outcomes in these babies are purported to be due fetal programming to adapt to the intrauterine environment, which lead to maladaptation. ${ }^{10}$

Fifth, an effective intervention must exist. As noted by ACOG, the following interventions do not decrease the likelihood of suboptimal growth: nutrient treatment, zinc or calcium supplementation, plasma volume expansion, mater- nal oxygen therapy, antihypertensive medications, and heparin or aspirin therapy. Though IUGR is unpreventable, the associated morbidity and mortality can be ameliorated. Antepartum testing with appropriate interventions lowers mortality. ${ }^{11}$ According to the ACOG practice bulletin, ${ }^{1}$ the corrected perinatal mortality with IUGR is 21.3 per 1000 births if these fetuses are undiagnosed and do not have antenatal tests. However, if they are detected and have antenatal surveillance, the perinatal mortality rate decreases by $60 \%$ to 8.4 per $1000 .{ }^{1}$ A meta-analysis of 18 trials with over 10,000 women concluded that use of Doppler ultrasound in high-risk pregnancies reduced the risk of perinatal death and resulted in less obstetric interventions like induction of labor and cesarean delivery. ${ }^{12}$ The number needed to monitor to prevent one death is 203 (95\% confidence interval of 103 to 4352). If fetal well-being is not assured and preterm delivery is indicated, then the effective interventions include administration of corticosteroids and transfer for delivery at a tertiary center, with a neonatal intensive care unit. ${ }^{13}$

The sixth criterion is that the screening test must be costeffective. A PubMed search, using combinations of the terms "cost effective," "intrauterine growth restriction," "small for gestational age," and "estimate fetal weight," identified a paucity of publications on the cost-effectiveness of screening for growth restriction. Such an analysis seems daunting because growth restriction is associated with both stillbirth ${ }^{1}$ and hypoxic ischemic injuries, ${ }^{14}$ which are leading causes of obstetric litigation. ${ }^{15}$ It is noteworthy that Gilbert and Danielsen $^{16}$ reported that with newborns delivered at 30 to 41 weeks, the hospital charges for growth-restricted newborns are significantly higher than for those with adequate growth. This does not assure that screening for suboptimal growth will be cost-effective but suggests it might be.

Seventh, facilities must be readily available to diagnose the disease. When the clinical estimate is $<2500 \mathrm{~g}$ or if the GA is $<37$ weeks, then clinical estimate is not as reliable as SEFW. ${ }^{17}$ Factors that make fundal height assessment difficult may include maternal obesity ${ }^{18}$ as well as the inability to determine if $A C$ is $<10 \%$ for GA, a criteria for IUGR. ${ }^{1}$ SEFW can identify IUGR and those measurements are most accurate when done by registered diagnostic medical sonographers, rather than residents, obstetricians, or maternal fetal medicine subspecialists. ${ }^{19,20}$ Although detection of anomalies is optimum at tertiary centers, ${ }^{21}$ there is no suggestion that SEFW should be done solely at these centers. ${ }^{20}$ According to the national vital statistics reports, $67 \%$ of women with live births had sonographic examinations during their pregnancy. $^{22}$ Thus, it seems that there are facilities available to do sonographic examinations and diagnose the disease.

The eighth criterion of a valuable screening test is that facilities for treatment should be available. When IUGR is detected then antepartum testing should be initiated. ${ }^{1,11}$ According to ACOG, a nonstress test, a contraction stress test, or a modified or complete biophysical profile are reliable surveillance modalities to assess fetal well-being. ${ }^{11}$ Because nonstress test and contraction stress test involve fetal heart rate monitoring, which is the predominant modality to assess fetal well-being during labor, ${ }^{23}$ these treatment options are 
Table 1 Screening for Intrauterine Growth Restriction among Uncomplicated Pregnancies

\begin{tabular}{|c|c|c|c|}
\hline & $\begin{array}{l}\text { Characteristics of } \\
\text { Screening Test }\end{array}$ & Applicable & Comments \\
\hline 1 & $\begin{array}{l}\text { The disease should be } \\
\text { medically important }\end{array}$ & Yes & $\begin{array}{l}\text { Morbidity and mortality with suboptimal growth are } \\
\text { well known }{ }^{1,6}\end{array}$ \\
\hline 2 & $\begin{array}{l}\text { The disease is clearly } \\
\text { defined }\end{array}$ & Yes & $\begin{array}{l}\text { Though there are several definitions of suboptimal } \\
\text { growth ( }<1 \%,<3 \%,<10 \% \text {, or }<15 \%) \text {, both ACOG and } \\
\text { RCOG define SGA as birth weight below } 10 \% \text { for } \\
\text { gestational age } 1,7,8\end{array}$ \\
\hline 3 & $\begin{array}{l}\text { The prevalence } \\
\text { reasonably well known }\end{array}$ & Yes & $\begin{array}{l}\text { Based on the criteria to define SGA (see } 2 \text { above), the } \\
\text { prevalence is well known }\end{array}$ \\
\hline 4 & $\begin{array}{l}\text { The natural history } \\
\text { should be known }\end{array}$ & Yes & $\begin{array}{l}\text { Abnormal invasion of cytotrophoblasts, decreased } \\
\text { capillary surface area; reduced fetal urinary flow } \\
\text { rate }^{9} \text { and oligohydramnios; cord compression and } \\
\text { stillbirth }^{1} \text {; long-term morbidity is due to fetal origin } \\
\text { of disease }\end{array}$ \\
\hline 5 & $\begin{array}{l}\text { An effective intervention } \\
\text { must exist }\end{array}$ & Yes & $\begin{array}{l}\text { Although there are no preventive measures to de- } \\
\text { crease the likelihood of growth restriction, there are } \\
\text { interventions (antenatal testing, Doppler of umbili- } \\
\text { cal artery, corticosteroids, inductions, transfer to } \\
\text { hospital with neonatal intensive care unit and deliv- } \\
\text { ery) that improve the morbidity and mortality linked } \\
\text { with aberrant growth } 1,11-13\end{array}$ \\
\hline 6 & $\begin{array}{l}\text { Screening program must } \\
\text { be cost effective }\end{array}$ & Unknown & $\begin{array}{l}\text { PubMed search (December } 2010 \text { ) did not identify } \\
\text { publication that ascertained if screening uncompli- } \\
\text { cated pregnancies for IUGR is cost-efficient }\end{array}$ \\
\hline 7 & $\begin{array}{l}\text { Facilities for diagnosis } \\
\text { must be readily available }\end{array}$ & Yes & $\begin{array}{l}\text { Over } 65 \% \text { of women giving live births have sono- } \\
\text { graphic examinations during pregnancy }{ }^{23} \text {; thus, it is } \\
\text { feasible for the majority to have sonographic esti- } \\
\text { mate in birth weight in the third trimester }\end{array}$ \\
\hline 8 & $\begin{array}{l}\text { Facilities for treatment } \\
\text { must be readily available }\end{array}$ & Yes & $\begin{array}{l}\text { Though there are no treatment to prevent abnormal } \\
\text { growth, antepartum testing (nonstress or contrac- } \\
\text { tion stress tests), administration of corticosteroids, } \\
\text { induction or transfer to tertiary center if preterm } \\
\text { delivery is indicated is available, } 1,11,13 \text { all of which } \\
\text { improve associated morbidity and mortality }\end{array}$ \\
\hline 9 & The test must do its job & Possibly & $\begin{array}{l}\text { The likelihood ratio for the detection of IUGR is over } \\
10 \text {, albeit in high-risk pregnancies } 27\end{array}$ \\
\hline 10 & The test must be safe & Yes & $\begin{array}{l}\text { ACOG and AIUM attest to the safety of sonographic } \\
\text { examinations during pregnancy } 3,28\end{array}$ \\
\hline 11 & $\begin{array}{l}\text { Test must have a reason- } \\
\text { able cutoff level defined }\end{array}$ & Yes & $\begin{array}{l}\text { Both ACOG and RCOG consider abdominal circum- } \\
\text { ference or estimated fetal weight }<10 \% \text { for gesta- } \\
\text { tional age as criteria for IUGR }\end{array}$ \\
\hline 12 & The test must be valid & Yes & $\begin{array}{l}\text { About } 80 \% \text { of newborns have birth weight }<10 \% \text { for } \\
\text { gestational age; when prenatal, they were suspected } \\
\text { of being IUGR }\end{array}$ \\
\hline 13 & The test must be reliable & Uncertain & $\begin{array}{l}\text { Although earlier studies indicated that the meas- } \\
\text { urements of biometric parameters are not reliable, } \\
\text { the low interobserver variability in recent studies is } \\
\text { reassuring } 37,38\end{array}$ \\
\hline 14 & Lead-time bias & Unknown & Need randomized clinical trial \\
\hline 15 & Length bias & Unknown & Need randomized clinical trial \\
\hline
\end{tabular}

ACOG, American College of Obstetrician and Gynecologists; AIUM, American Institute of Ultrasound and Medicine; IUGR, intrauterine growth restriction; RCOG, Royal College of Obstetrician and Gynaecologists; SGA, small for gestational age.

readily available. Administration of corticosteroids and transfer to a tertiary care facility are accepted effective treatment for spontaneous preterm labor, ${ }^{24}$ and they should be equally efficacious for indicated preterm delivery secondary to IUGR and comorbidities like absent or reverse end diastolic flow in the umbilical artery. ${ }^{13}$

The screening test must do its job is the ninth criterion. According to the guidelines established by the Evidence-Based 
Medicine Working Group, a diagnostic test is useful if the likelihood ratio (LR) is at least 10 or less than $0.1 .^{25}$ Prior publications have reported that the LR for detection of IUGR has ranged from 2.3 to $11 .^{26,27}$ The reason for the variation in the LR includes that the sonographic examination were being done by physicians with varying years of experience. Consistent with a review article on the topic, ${ }^{20}$ when EFW is done by registered diagnostic medical sonographers, the LR was 11. Thus, it seems sonographic estimates can detect suboptimal growth, but additional studies are needed to determine the factors that enhance the detection and whether it can be done in low-risk pregnancies.

The 10th criterion is the safety of the test. Ultrasound examination during pregnancy is considered safe as evidenced by the practice guideline published by American Institute of Ultrasound in Medicine ${ }^{28}$ and the ACOG. ${ }^{3}$ In 2009, ACOG confirmed that "ultrasonography is safe for the fetus when used appropriately and when medical information about pregnancy is needed." ${ }^{3}$ There is, however, a potential for small risk. The practice bulletin does note that energy produced by ultrasound and delivered to the fetus cannot be assumed to be completely innocuous. Under laboratory conditions, ultrasonography can produce physical effects, such a mechanical vibration, referred to as "cavitation," or an increase in tissue temperature. ${ }^{3}$

Earlier reports have observed that with ultrasound examinations there were complications like IUGR, ${ }^{29}$ delayed speech, ${ }^{30}$ dyslexia ${ }^{31}$ and left-handedness. ${ }^{32}$ But a meta-analysis of nine RCTs comparing routine versus selective ultrasound in early pregnancy noted that there was no significant difference in the two groups with regards to low Apgar scores, low birth weight, admission to a neonatal intensive unit, corrected (excluding anomalies) perinatal mortality, and neurodevelopmental outcomes such as poor reading, dyslexia, or hearing defect. ${ }^{33}$

It is significant that the World Health Organization Ethics Review Board has approved a multicountry prospective study on fetal growth with seven serial ultrasound exams during pregnancy. This decision was based on a meta-analysis of 41 reports that concluded that sonographic examinations during pregnancy are not associated with adverse maternal or perinatal effects, impaired physical or neurological development, increased risk s of malignancies in childhood, or subnormal intellectual performance. ${ }^{34}$

The 11th criterion for a screening test is that it must have a reasonable and well-defined cutoff level. According to ACOG and RCOG, AC or estimated fetal weight $<10 \%$ for $G A^{1,13}$ is consistent with IUGR. A recent report confirmed that these cutoffs do identify pregnancies that are at significant risk for oligohydramnios, cesarean delivery for nonreassuring fetal heart rate, admission to a neonatal intensive care unit, and newborns with an actual birth weight $<10 \%$ for $G A .{ }^{35}$ Due to a small sample size $(n=410)$, the investigators did not demonstrate that fetuses with sonographic suspicion of IUGR are at increased risk of composite morbidity like Apgar score $<4$ at 5 minutes, umbilical arterial $\mathrm{pH}<7.00$, neonatal seizures within 24 hours, grade III or IV intraventricular hemorrhage, or proven sepsis or death within 28 hours. Additional studies are needed to link AC or EFW $<10 \%$ with composite neonatal morbidity.

The screening test should be valid is the 12th criteria. As noted by Grimes and Schulz, validity is the ability of a test to measure what it sets out to measure, usually differentiating between those with and without the disease present. ${ }^{5}$ According to Chauhan et al, when IUGR was suspected sonographically, $80 \%$ of the newborns actually weighed $<10 \%$ for GA, as compared with $14 \%$, when growth was considered normal. ${ }^{35}$ Thus, it does seem that the SEFW below the $10 \%$ for GA is a valid screening test for IUGR.

The 13th criterion is whether the test is reliable. An initial report $^{36}$ suggested that the interobserver variability for measuring biometric parameters was excessive, rendering SEFW unreliable. Recent publications, however, note that the intra- and interobserver variability for paramedics in Bangladesh, with no prior sonographic experience, is reliable. ${ }^{37}$ Similarly, Rijken et al ${ }^{38}$ documented that local health workers in the Thailand-Myanmar border can obtain biometric measurements with an interclass coefficient $>0.99$, suggesting that the diagnostic test is reliable. We do acknowledge that retrospective multicenter studies have noted that detection of growth restriction is not reliable among women with hypertensive disease. ${ }^{26}$ The difference between recent publications on interobserver variability and multicenter studies is the inherent bias and shortcoming of retrospective studies. Though we agree that at present there are insufficient or conflicting reports on the reliability of detecting IUGR, it is important that in the randomized trial by McKenna et al, ${ }^{2}$ the midwives were able to lower the rate of SGA significantly with just 3 months of training in sonographic examinations.

The 14th and 15th criteria for a useful screening test are lead time and length bias. As noted by Grimes and Schulz, ${ }^{5}$ leadtime bias is a spurious increase in longevity attributed to screening and length bias is improvement in longevity that is not related to the test. The way to rectify these biases is to do an RCT. Although the randomized trial by McKenna et $\mathrm{al}^{2}$ did reduce the rate of SGA, it lacked sufficient sample size to show improvement in longevity, which the authors acknowledged. They calculated that 30,000 women would need to be randomized for a trial to have sufficient power to detect a $30 \%$ reduction in perinatal mortality rates between the two groups. Before such a large RCT is undertaken, we suggest a multicenter randomized trial with a composite morbidity as the primary outcome defined as, at least one of the following: admission to a neonatal intensive care unit for at least 48 hours, hypoglycemia, thrombocytopenia at term, respiratory distress syndrome, necrotizing enterocolitis, intraventricular hemorrhage (grades III or IV), sepsis, or perinatal death (stillbirth after randomization or death before newborn's discharge from the hospital).

The inclusion and exclusion criteria for the proposed randomized trial are listed in - Table $\mathbf{2}$. As with the protocol utilized by McKenna et al, ${ }^{2}$ the expectant management group will have sonographic examination in the third trimester if there is clinical suspicion for fetal growth or amniotic fluid abnormalities, decreased fetal movements, or other obstetric indications like preterm labor or hypertensive disease. The intervention group will have sonographic examinations, 
Table 2 Enrollment Criteria for Proposed Randomized Trial

\begin{tabular}{|c|c|}
\hline Inclusion Criteria & Exclusion Criteria \\
\hline $\begin{array}{l}\text { - Nonanomalous singleton } \\
\text { - Fetal anatomy ultrasound by } 22 \text { weeks } \\
\text { - Expected third-trimester care and delivery } \\
\text { at the participating hospital }\end{array}$ & $\begin{array}{l}\text { - Autoimmune disorders (antiphospholipid antibody, lupus, } \\
\text { rheumatoid arthritis, scleroderma) } \\
\text { - Cerclage in the index pregnancy } \\
\text { - Diabetes mellitus-gestational or pregestational } \\
\text { - Enrollment in another randomized clinical trial } \\
\text { - Hematologic disorders (coagulation defects, sickle cell disease, } \\
\text { - } \text { Hrombocytopenia, thrombophilia) } \\
\text { - HIV } \\
\text { - Institutionalized individuals (prisoners) } \\
\text { - Prior obstetric history of: ( } 1 \text { ) intrauterine growth restriction, } \\
\text { (2) preterm birth before } 34 \text { weeks, }(3) \text { severe preeclampsia, } \\
\text { eclampsia, HELLP syndrome, and (4) stillbirth after } 24 \text { weeks } \\
\text { or neonatal death } \\
\text { - Preterm labor or ruptured membranes before randomization } \\
\text { - Psychiatric disorder (bipolar, depression) on medication } \\
\text { - Placenta previa/third-trimester bleeding } \\
\text { - Renal insufficiency (serum creatinine > } 1.5 \text { mg/dL) } \\
\text { - Restrictive lung disease } \\
\text { - Fetal red blood cell isoimmunization } \\
\text { - Seizure disorder on medication } \\
\text { - Thyroid disease on medication }\end{array}$ \\
\hline
\end{tabular}

HELLP, hemolysis, elevated liver enzymes, and low platelet count.

evaluating fetal growth and amniotic fluid, at 30 to 32 weeks and at 36 to 37 weeks. In both groups, indications for delivery at 37 to 39 weeks will include abnormalities of amniotic fluid (oligohydramnios or hydramnios), or IUGR. Considering the vagaries of SEFW ${ }^{20}$ and that all of the women in the trial are uncomplicated, it is possible that many of newborns suspected of being growth restricted will not be, leading to unnecessary induction and iatrogenic neonatal morbidity. These theoretical concerns are valid, but it is noteworthy that in the randomized trial by McKenna and colleagues, ${ }^{2}$ the rate of SGA was decreased significantly, without concomitant increase in induction rate or admission to neonatal intensive care unit, a surrogate for neonatal morbidity.

A published report ${ }^{39}$ points out that the likelihood of combined neonatal morbidity (hypoglycemia, respiratory distress syndrome, thrombocytopenia, sepsis, intraventricular hemorrhage, and intubation) was $22 \%$ with growth restriction with otherwise uncomplicated pregnancies versus $2 \%$ among those with normal growth. Accordingly, in a population with a $10 \%$ rate of growth restriction, the overall rate of the combined neonatal morbidity is $4.1 \%$. To have $80 \%$ power to observe a $36 \%$ decrease (from 4.1 to $2.6 \%$ ) in composite perinatal morbidity, we would need 2966 patients in each group $(\alpha=0.05)$. Assuming a loss rate of $10 \%$, the RCT needs to recruit 6000 uncomplicated patients. To obtain this sample size, 12,000 women need to be screened, assuming $\sim 50 \%$ of pregnancies are complicated or will decline participation.

\section{Discussion}

Compared with those with appropriate growth, the increased perinatal morbidity and mortality with growth-restricted newborns is undeniable. At least 10 interventions (bed rest, aspirin, nutrient supplements with calcium or zinc, maternal oxygenation, heparin, plasma volume expansion, calcium channel blockers, hormonal therapy, and smoking cessation) have been tried, but all have proven unsuccessful without decreasing the rate of IUGR or its associated complications. ${ }^{1}$ Now there is a CONSORT compliant RCT that unequivocally demonstrated a reduction in the rate of IUGR, with two additional sonographic examinations in the third trimester. ${ }^{2}$ Despite the promising results, sonographic estimated fetal weight after 30 weeks is not being used as a screening test. ${ }^{1}$ Thus, we reviewed the literature to determine what is present and lacking for it to be a successful screening test.

We described 15 important characteristics of an ideal screening test. SEFW to detect IUGR meets 66\% (10/15) of these criteria (-Table $\mathbf{1}$ ), which is reassuring. The criteria it does not meet currently, however, are worth emphasizing. A cost-effective analysis is warranted and should be done. Additional studies of IUGR in low-risk populations are needed to determine that among uncomplicated women, if SEFW can reliably identify IUGR, as it can with high-risk pregnancies. Although there are interobserver variability reports on measurements of biometric parameters, investigators should ascertain if detection of IUGR is reliable. The most important finding, however, of this review is that a multicenter RCT is warranted with the primary objective of reducing the combined morbidity linked with IUGR. A formidable concerted multicenter study that screens 12,000 women and randomizes $\sim 6000$ is urgently needed. Such a study is justified, even at term. Neonatal charges to treat a growth-restricted newborn are about $\$ 16,000$ more than those for a newborn with appropriate growth, and the likelihood of neonatal seizures, proven sepsis, grade III or IV intraventricular hemorrhage, and death within 28 days are significantly higher. ${ }^{16}$ 
Strategies aimed at screening growth-restricted fetuses should address the results of GRIT (Growth Restriction Intervention Trial) trial, which randomized women with "fetal compromise" to immediate versus delayed delivery. ${ }^{40,41}$ Of the 548 women enrolled, the likelihood of death before discharge was similar in the two groups $(10 \%$ in immediate versus $9 \%$ in delayed group; odds ratio $1.1 ; 95 \%$ confidence interval 0.6 to 1.8 ). Additionally at 2 years, the overall rate of death or disability was not significantly different between the groups (19\% in immediate and $16 \%$ in delayed group; adjusted odds ratio of $1.1 ; 95 \%$ confidence interval 0.7 to 1.8 ). These reports ${ }^{40,41}$ suggest that there may not be any benefit of screening for growth restriction, but we do not think the results are applicable to uncomplicated pregnancies. In GRIT trial, $7 \%^{39}$ of women had multiple pregnancies, 36\% (196) were randomized at 24 to 30 weeks, and 43\% (234) had hypertension. Because the GRIT trial included preterm patients and had medical complications, we think our proposed randomized study should be undertaken.

There is evidence that impaired intrauterine growth is linked with several major diseases in adult life, like coronary heart disease, hypertension, and type 2 diabetes. The suggestion, referred to as "fetal programming," is that intrauterine environment provides stimulus or insult at a critical, sensitive period of early life, which has permanent effects on structure, physiology, and metabolism. ${ }^{42,43}$ Screening with sonographic examinations in the third trimester and inducing if abnormalities were noted significantly decreased the rate of newborns with suboptimal growth. ${ }^{2}$ Thus one could speculate that such program will decrease disease in adult life, but this would need long-term follow-up of newborns, which would be a Herculean task.

In summary, it may be feasible to reduce the rate of IUGR and its associated morbidity and mortality. At present, however, routine screening of uncomplicated women with sonographic estimated fetal weight in the third trimester is not recommended. An RCT and cost-effective analysis are needed before third-trimester sonographic estimate weight can be considered a successful screening test.

\section{Note}

Presented at Central Association of Obstetricians and Gynecologists at Nassau, Bahamas in October 2011.

\section{References}

1 American College of Obstetricians and Gynecologists. Intrauterine Growth Restriction. Washington, DC: American College of Obstetricians and Gynecologists; 2000. Reaffirmed 2010

2 McKenna D, Tharmaratnam S, Mahsud S, Bailie C, Harper A, Dornan J. A randomized trial using ultrasound to identify the high-risk fetus in a low-risk population. Obstet Gynecol 2003; 101:626-632

3 American College of Obstetricians and Gynecologists. Ultrasonography in Pregnancy. Washington, DC: American College of Obstetricians and Gynecologists; 2009
4 Rouse DJ, Owen J, Goldenberg RL. Routine maternal platelet count: an assessment of a technologically driven screening practice. Am J Obstet Gynecol 1998;179(3 Pt 1):573-576

5 Grimes DA, Schulz KF. Uses and abuses of screening tests. Lancet 2002;359:881-884

6 Chen HY, Chauhan SP, Ward TC, Mori N, Gass ET, Cisler RA. Aberrant fetal growth and early, late, and postneonatal mortality: an analysis of Milwaukee births, 1996-2007. Am J Obstet Gynecol 2011;204:261, e1-e261, e10

7 Chauhan SP, Magann EF. Screening for fetal growth restriction. Clin Obstet Gynecol 2006;49:284-294

8 Chauhan SP, Gupta LM, Hendrix NW, Berghella V; American College of Obstetricians and Gynecologists. Intrauterine growth restriction: comparison of American College of Obstetricians and Gynecologists practice bulletin with other national guidelines. Am J Obstet Gynecol 2009;200:409, e1-e6

9 Resnik R, Creasy RK. Intrauterine growth restriction. In: Creasy RK, Resnik R, Iams JD, Lockwood CJ, Moore TJ, eds. Maternal-Fetal Medicine: Principles and Practice. 6th ed. Philadelphia, PA: Saunders, Elsevier; 2009:636-650

10 Godfrey KM, Barker DJ. Fetal nutrition and adult disease. Am J Clin Nutr 2000;71:1344S-1352S

11 American College of Obstetricians and Gynecologists. Antepartum Fetal Surveillance. Washington DC: American College of Obstetricians and Gynecologists; 1999. Reaffirmed 2009

12 Alfirevic Z, Stampalija T, Gyte GML. Fetal and umbilical Doppler ultrasound in high-risk pregnancies. Cochrane Database Syst Rev 2010;(1):CD007529

13 Royal College of Obstetricians and Gynaecologists. Green-top guidelines. 2007. Available at: http://www.rcog.org.uk/womens-health/ investigation-and-management-small-gestational-age-fetus-greentop-31. Accessed March 1, 2008

14 American College of Obstetricians and Gynecologists' Task Force on National Encephalopathy and Cerebral Palsy, American College of Obstetricians and Gynecologists, American Academy of Pediatrics. Neonatal Encephalopathy and Cerebral Palsy: Defining the Pathogenesis and Pathophysiology. Washington: American College of Obstetricians and Gynecologists; 2003

15 Klagholz J, Strunk AL. Overview of the 2009 ACOG Survey on Professional Liability. Available at: http://www.acog.org/About_ ACOG/ACOG_Departments/Professional_Liability/2012_Survey_ Results. Retrieved October, 162010

16 Gilbert WM, Danielsen B. Pregnancy outcomes associated with intrauterine growth restriction. Am J Obstet Gynecol 2003; 188:1596-1599; discussion 1599-1601

17 Chauhan SP, Hendrix NW, Magann EF, Morrison JC, Kenney SP, Devoe LD. Limitations of clinical and sonographic estimates of birth weight: experience with 1034 parturients. Obstet Gynecol 1998;91:72-77

18 Fox NS, Bhavsar V, Saltzman DH, Rebarber A, Chasen ST. Influence of maternal body mass index on the clinical estimation of fetal weight in term pregnancies. Obstet Gynecol 2009;113: 641-645

19 Humphries J, Reynolds D, Bell-Scarbrough L, Lynn N, Scardo JA Chauhan SP. Sonographic estimate of birth weight: relative accuracy of sonographers versus maternal-fetal medicine specialists. J Matern Fetal Neonatal Med 2002;11:108-112

20 Chauhan SP, Hendrix NW, Magann EF, Morrison JC, Scardo JA, Berghella V. A review of sonographic estimate of fetal weight: vagaries of accuracy. J Matern Fetal Neonatal Med 2005;18: 211-220

21 Crane JP, LeFevre ML, Winborn RC, et al; The RADIUS Study Group. A randomized trial of prenatal ultrasonographic screening: impact on the detection, management, and outcome of anomalous fetuses. Am J Obstet Gynecol 1994;171:392-399

22 Martin JA, Hamilton BE, Sutton PD, et al. Births: Final Data for 2003. National Vital Statistics Reports. Vol. 54, No. 2. Hyattsville, MD: National Center for Health Statistics; 2005 
23 Chen H-Y, Chauhan SP, Ananth CV, Vintzileos AM, Abuhamad AZ. Electronic fetal heart rate monitoring and its relationship to neonatal and infant mortality in the United States. Am J Obstet Gynecol 2011;204:491, e1-e10

24 American College of Obstetricians and Gynecologists. Management of Preterm Labor. Washington DC: American College of Obstetricians and Gynecologists; 2003. Reaffirmed 2011

25 Jaeschke R, Guyatt GH, Sackett DL. Users' guides to the medical literature. III. How to use an article about a diagnostic test. B. What are the results and will they help me in caring for my patients? The Evidence-Based Medicine Working Group. JAMA 1994;271: 703-707

26 Chauhan SP, Magann EF, Velthius S, et al. Detection of fetal growth restriction in patients with chronic hypertension: is it feasible? J Matern Fetal Neonatal Med 2003;14:324-328

27 Chauhan SP, Parker D, Shields D, Sanderson M, Cole JH, Scardo JA. Sonographic estimate of birth weight among high-risk patients: feasibility and factors influencing accuracy. Am J Obstet Gynecol 2006;195:601-606

28 American Institute of Ultrasound in Medicine. Practice Guideline for the Performance of Obstetric Ultrasound Examinations. Laurel, MD: American Institute of Ultrasound in Medicine; 2007

29 Newnham JP, Evans SF, Michael CA, Stanley FJ, Landau LI. Effects of frequent ultrasound during pregnancy: a randomised controlled trial. Lancet 1993;342:887-891

30 Campbell JD, Elford RW, Brant RF. Case-control study of prenatal ultrasonography exposure in children with delayed speech. CMAJ 1993; $149: 1435-1440$

31 Stark CR, Orleans M, Haverkamp AD, Murphy J. Short- and longterm risks after exposure to diagnostic ultrasound in utero. Obstet Gynecol 1984;63:194-200

32 Salvesen KA, Vatten LJ, Eik-Nes SH, Hugdahl K, Bakketeig LS. Routine ultrasonography in utero and subsequent handedness and neurological development. BMJ 1993;307:159-164
33 Whitworth M, Bricker L, Neilson JP, Dowswell T. Ultrasound for fetal assessment in early pregnancy. Cochrane Database Syst Rev 2010;(4):CD007058

34 Torloni MR, Vedmedovska N, Merialdi M; , et al; ISUOG-WHO Fetal Growth Study Group. Safety of ultrasonography in pregnancy: WHO systematic review of the literature and meta-analysis. Ultrasound Obstet Gynecol 2009;33:599-608

35 Chauhan SP, Taylor M, Shields D, Parker D, Scardo JA, Magann EF. Intrauterine growth restriction and oligohydramnios among highrisk patients. Am J Perinatol 2007;24:215-221

36 Harstad TW, Buschang PH, Little BB, Santos-Ramos R, Twickler D, Brown CE. Ultrasound anthropometric reliability. J Clin Ultrasound 1994;22:531-534

37 Neufeld LM, Wagatsuma Y, Hussain R, Begum M, Frongillo EA. Measurement error for ultrasound fetal biometry performed by paramedics in rural Bangladesh. Ultrasound Obstet Gynecol 2009;34:387-394

38 Rijken MJ, Lee SJ, Boel ME, et al. Obstetric ultrasound scanning by local health workers in a refugee camp on the Thai-Burmese border. Ultrasound Obstet Gynecol 2009;34:395-403

39 Minior VK, Divon MY. Fetal growth restriction at term: myth or reality? Obstet Gynecol 1998;92:57-60

40 GRIT Study Group. A randomised trial of timed delivery for the compromised preterm fetus: short term outcomes and Bayesian interpretation. BJOG 2003;110:27-32

41 Thornton JG, Hornbuckle J, Vail A, Spiegelhalter DJ, Levene M; GRIT study group. Infant wellbeing at 2 years of age in the Growth Restriction Intervention Trial (GRIT): multicentred randomised controlled trial. Lancet 2004;364:513-520

42 Barker DJ, Osmond C, Golding J, Kuh D, Wadsworth ME. Growth in utero, blood pressure in childhood and adult life, and mortality from cardiovascular disease. BMJ 1989;298: 564-567

43 Godfrey KM, Barker DJ. Fetal nutrition and adult disease. Am J Clin Nutr 2000;71(5, Suppl):1344S-1352S 